\title{
ATIVISMO PÚBLICO COMO ESTRATÉGIA DE AÇÃO DO CAMPESINATO BRASILEIRO: O CASO DO MOVIMENTO DE MULHERES CAMPONESAS (MMC)
}

\author{
PUBLIC ACTIVISM AS A SOCIAL STRATEGY OF THE BRAZILIAN \\ PEASANTRY: THE MOVEMENT OF PEASANT WOMEN
}

Maria Clara Capel de Ataídes ${ }^{1}$

\begin{abstract}
RESUMO
O artigo investiga a temática do ativismo público como estratégia social do Movimento de Mulheres Camponesas. Explora, para tanto, seu panorama histórico cultural como um movimento contra-hegemônico. Para uma análise das estratégias de ação no âmbito dos movimentos sociais, avalia as organizações legítimas dos povos ingleses no século XVIII, que agiam fundados em uma economia moral, bem como as ações do campesinato no Brasil. Parte-se da hipótese de que há uma racionalidade nas propostas de ação do Movimento de Mulheres Camponesas e de que sua natureza dinâmica deve ser analisada à luz dos processos historiográficos.
\end{abstract}

Palavras-chave: Movimento de Mulheres Camponesas, Movimentos Sociais, Ativismo Público, Estratégias de Ação Social.

\begin{abstract}
This paper analyzes the issue of public activism as a social strategy of the Movement of Peasant Women. Explores, therefore, its historical overview as a counter-hegemonic movement. For an analysis of the strategical actions within the social movements, evaluates the legitimate organizations of the English people in the eighteenth century, who acted founded on a moral economy, and the peasantry actions in Brazil. Starts with the hypothesis that there is rationality in the proposals of the Movement of Peasant Women and that it's dynamic nature must be analyzed under the light of historiographical processes.
\end{abstract}

Keywords: Movement of Peasant Women, Social Movements, Public Activism, Social Strategies

\footnotetext{
${ }^{1}$ Mestranda em Direito Agrário pela Universidade Federal de Goiás - UFG, Goiás (Brasil). Bolsista FAPEG Fundação de Amparo à Pesquisa do Estado de Goiás. E-mail: mariaclaracapel@ gmail.com
} 


\section{Panorama histórico-cultural do surgimento do Movimento de Mulheres Camponesas}

A partir da década de 70 não é possível que se fale em uma autonomia da agricultura no Brasil. Isso se dá em decorrência da modernização da agricultura e da substituição do complexo latifúndio/minifúndio por um complexo agroindustrial. A realidade do complexo latifúndio/minifúndio, que antes funcionava por meio de agentes do capital, como os comerciantes das cidades, passa a ser a de uma agricultura que fala por meio do complexo agroindustrial. A influência do capital se dá tanto na indústria que produz para a agricultura, como naquela que consome produtos agrícolas. Há, por isso, a partir das décadas de 60 e 70, um deslocamento na importância da terra-matéria para a terra-capital.

Esse processo de modernização gera uma mudança no discurso das oligarquias, que antes vinculadas à terra-matéria passam, posteriormente, a considerar o complexo agroindustrial e a terra como capital. Uma das influências desse processo é a Revolução Verde ocorrida nos Estados Unidos que, para gerar um aumento da produtividade, desenvolveu pesquisas em sementes, insumos agrícolas e máquinas. O que atesta Geraldo Müller, nesse sentido, é que embora no início dos anos 70 já houvesse uma interdependência entre os setores agrícolas e industriais no Brasil, o que se designa de complexo agroindustrial, não houve uma fusão entre a agricultura e a indústria, mas hegemonia desta em detrimento daquela:

Neste sentido, a terra subordina-se ao capital industrial e financeiro. $\mathrm{Na}$ verdade, esta formulação é imprecisa. É o trabalho agrícola que se subordina ao capital, no contexto de uma industrialização crescente da agricultura, processo no qual a terra-matéria perde suas forças determinadoras das condições de produção em favor da terra-capital. (MÜLLER, 1989, p.39).

Moacir Palmeira (2011) atesta que o complexo agroindustrial se formou por meio da absorção de crédito agrícola, de insumos modernos, da mecanização da produção, do aumento da produtividade e da quantidade de matérias-primas. A industrialização da agricultura, que ocorreu sem que fosse modificada a estrutura da propriedade rural, gerou efeitos desastrosos no campo como a concentração fundiária, a desigualdade de renda, o êxodo rural, o aumento da exploração da força de trabalho em atividades agrícolas e o crescimento da taxa de autoexploração nas pequenas propriedades, bem como a piora da qualidade de vida dos 
trabalhadores do campo. Por esse motivo utiliza-se a expressão "modernização conservadora" para descrever esse fenômeno (PALMEIRA, 2011, p. 87).

O processo mencionado, entretanto, não ocorreu de maneira homogênea no Brasil, mas mediante divergências em função de fatores como a região, os produtos comercializados, as políticas de crédito rural e os fluxos com o exterior. Exemplo desses produtos é a soja, que por não ser processada é colocada in natura no mercado, o que confere maior autonomia aos proprietários de terras e uma menor subordinação à indústria. Para Müller (1989), essa modernização parcial da agricultura tradicional, com a permanência de faixas atrasadas, agricultura em distintos estágios de industrialização ou que possui a união de fatores modernos e atrasados, é uma característica estrutural brasileira.

Esse processo não homogêneo também se verifica na análise realizada por José de Souza Martins (1997) da ocupação das fronteiras pelas frentes de expansão e pelas frentes pioneiras. A frente de expansão, frente demográfica, acontece por meio de uma relação que não é a do capitalismo clássico, mas que está eminentemente vinculada ao capital comercial, ao parceiro e ao camponês. A frente pioneira, por outro lado, frente econômica, relaciona-se ao capital industrial, à burguesia, ao operário e ao capitalismo de trabalho. A análise da ocupação do território brasileiro por essas frentes possibilita que se enxergue a complexidade da questão agrária, já que cada região foi afetada de maneira diferente por cada frente.

O autor mostra, além disso, que a história das frentes de expansão no Brasil é a história do milenarismo camponês, já que os movimentos milenaristas ou messiânicos ocorreram nessas frentes, em momentos em que os camponeses foram expulsos de suas terras ou estavam ameaçados de expulsão. Há, por isso, um imaginário místico na fronteira, que não é uma simples ampliação de território, mas local repleto de significado:

Nesse sonho se manifesta a grande transfiguração produzida pela fronteira, de certo modo definidora da sua singularidade temporária e histórica: tempo e espaço se fundem no espaço limite concebido ao mesmo tempo como tempo limite. É no fim que está propriamente o começo. (MARTINS, 1997, p. 203).

Esse processo variado é a demonstração de que, primeiramente, embora tenha acontecido um processo de industrialização formador de um complexo agroindustrial, não 
ocorreu uma total industrialização do campo e não se pode ignorar a existência de uma questão agrária no Brasil. Existe ainda, embora apagado e invisibilizado pelo capital, um camponês que resiste no campo e que utiliza seu conhecimento milenar de maneira a permanecer em seu território.

Maria de Nazareth Baudel Wanderley (1996), em uma análise do campesinato tradicional, expõe suas características. O camponês clássico, primeiramente, adota um sistema de policultura-pecuária, adequado e aperfeiçoado conforme suas práticas. Em segundo lugar, utiliza-se de saberes tradicionais e de uma cultura particular que garantem sua sobrevivência tanto no presente quanto para suas gerações futuras. Em terceiro lugar, o sistema de policultura-pecuária, embora aperfeiçoado para garantir a subsistência camponesa, não é autônomo, já que existe uma sociedade de interconhecimento que cria relações de dependência entre o camponês e outros atores do campo. Por último, a agricultura camponesa se diferencia da pequena agricultura e da agricultura de subsistência. Primeiro porque a agricultura camponesa, embora geralmente pequena e de poucos recursos, não é camponesa por ser pequena, mas pelos elementos já apontados. Segundo porque a agricultura de subsistência não necessariamente possui um projeto para futuras gerações, característica essencial da agricultura camponesa.

A autora destaca, ainda, que devido à complexidade histórica e cultural da realidade brasileira, o agricultor familiar possui, aqui, diferentes características. A primeira se constitui na fragilidade do sistema de produção, o que gerou uma precariedade estrutural. Essa precariedade impede que o camponês no Brasil desenvolva o sistema clássico de produção (a policultura-pecuária) e construa um patrimônio familiar. Há, também, uma dificuldade de inserção desse camponês no mercado, que se reflete em processos de campesinização, descampesinização e recampesinização, movimentos que integram as frentes de expansão e as frentes pioneiras acima mencionadas. A segunda peculiaridade se constitui em uma busca por território, a qual gera uma grande mobilidade do agricultor e sucessivos deslocamentos espaciais. Isso se dá por meio de uma pressão direta da grande propriedade ou de uma lógica interna própria da agricultura camponesa. Por último, o camponês brasileiro se caracteriza pelas atividades de alugar seu trabalho para terceiros, bem como de empregar trabalhadores alugados no estabelecimento familiar (WANDERLEY, 1996). 
É em meio ao contexto apresentado que, na década de 80, o Movimento de Mulheres Camponesas se consolida contrariamente à subordinação dos territórios e do sexo feminino ao capital industrial e financeiro. O movimento resgata a denominação "camponês", termo abandonado pela própria legislação, que de modo a trazer a questão para o âmbito estatal passa a utilizar a designação "agricultor familiar". É o que confirma Conte (2010), ao destacar que o termo camponês entrou em desuso para que não fossem lembradas as Ligas Camponesas de 1940 e 50. O termo é retomado, conforme a autora, pela Via Campesina, com o objetivo de que fossem lembradas as ligas e lutas camponesas de enfrentamento a um sistema hegemônico no campo.

A denominação "camponesa", conforme o portal eletrônico² do movimento, representa aquela que, em um núcleo familiar e de produção agrícola e artesanal autônoma, satisfaz suas necessidades familiares e de subsistência, bem como garante recursos necessários à compra de produtos e serviços que não produz. O movimento destaca a mulher camponesa como produtora de alimentos e garantidora da subsistência da família. Dentro dessa categoria estariam a pequena agricultora, a pescadora artesanal, a quebradeira de coco, as extrativistas, arrendatárias, meeiras, ribeirinhas, posseiras, bóias-frias, diaristas, parceiras, sem terra, acampadas e assentadas, assalariadas rurais e indígenas.

Tratar de seus integrantes como "camponeses", portanto, denota a resistência de um movimento contra-hegemônico que vai de encontro à ordem rural imposta e que busca adquirir as características do campesinato tradicional de maneira a permanecer e resistir no campo. É o que expressa uma das coordenadoras do movimento, em sua compreensão do que representa o camponês dentro do Movimento de Mulheres Camponesas:

Não tem como ser camponesa, sem ter um debate profundo sobre o território. O território camponês, da reforma agrária, dos ribeirinhos, envolve o jeito de vida, a cultura, a produção, tudo muito relacionado. Ela [a camponesa] vai na contramão desse modelo desenvolvimentista, que é os bens da natureza estarem a serviço do lucro e do capital. (...) Esses territórios para serem de campesinato tem que ser territórios livres de modelo de monocultivo, de veneno, de transgênicos, isso com certeza vai refletir nas relações sociais dentro desse grupo, desse território, na questão da violência, não tem como discutir agroecologia, se não discute também as relações com a natureza, entre seres humanos, não é só um modelo é um projeto de desenvolvimento a partir do saber popular, junto com técnicas e formação

\footnotetext{
${ }^{2}$ Portal Movimento de Mulheres Camponesas. Disponível em: http://www.mmcbrasil.com.br/site/ Acesso em: $10 / 07 / 2016$
} 
teórica, e respeito a uma sabedoria milenar que é do povo: resgate de sementes, melhoria de raças, que é o melhoramento natural dos galos, que é quando as galinhas ficam mirradas, por exemplo, o nosso povo sempre fez isso! Isso é cultura camponesa, isso é território, isso é desenvolvimento a partir do olhar desses camponeses, e não de uma ciência e uma ideologia de mercado. (TÁBOAS, 2014, p. 39).

As décadas de 70 e 80 no Brasil representam um período de efervescência de diversos movimentos sociais. Esses movimentos se insurgiam de modo contrário à realidade apresentada de subordinação da terra ao capital. A realidade feminista também cresce por meio de diversos movimentos e tratados internacionais ratificados pelo país. Para Meneghel (2013, p. 02), é na década de 1970 que a violência contra a mulher é visibilizada, de maneira que deixa de ser uma questão tratada no âmbito privado para constituir assunto de domínio do Estado. É na mesma década que surgem os primeiros movimentos feministas, e estes passam a ganhar repercussão na mídia, de modo que entre os anos de 1975 e 1979 acontece o que se denomina como a primeira fase do movimento. Nesse período foram problematizadas, principalmente, as liberdades democráticas, de maneira que é no ano de 1975, considerado como marco do início do Movimento Feminista no Brasil, que a questão da mulher é de fato colocada como obrigatória (RINALDI, 2007). Segundo Grossi (1988), é somente entre os anos de 1979 e 1982, quando se inicia a segunda fase do feminismo, que o tema da violência contra a mulher ganha espaço.

É nessa época que é realizada a primeira conferência mundial sobre a mulher, a Convenção sobre a Eliminação de Todas as Formas de Discriminação contra as Mulheres de 1981 (CEDAW - Convention on the Elimination of all forms of Discrimination Against Women), que foi adotada pela Assembleia da ONU, em 18 de dezembro de 1979, e entrou em vigor em 03 de setembro de 1981. A violência contra a mulher, contudo, só foi definida como violação aos direitos humanos durante a Conferência das Nações Unidas sobre Direitos Humanos, realizada em Viena, em 1993. Durante a década de 1990, o Brasil se tornou signatário de outras Convenções relativas aos direitos das mulheres, como a Convenção Americana dos Direitos Humanos, em 1992, e a Convenção Interamericana para Prevenir, Punir e Erradicar a Violência contra a Mulher (Convenção de Belém do Pará, 1994), em 1995.

No campo, esse é um período de resistência camponesa no qual diversos grupos camponeses se organizam em busca da luta pela terra e por direitos sociais. Ocorrem 
ocupações de terra que posteriormente geram a consolidação do Movimento de Trabalhadores Rurais Sem Terra, o MST (LUSA, 2010). O Movimento de Mulheres Camponesas nasceu em 1980, momento em que surgiam diversas organizações de mulheres no campo. Nasceu sob o nome de Movimento de Mulheres Agricultoras - MMA, em 25 de julho de 1981, em Santa Catarina, distrito de Itaberaba, município de Chapecó. Suas ações se iniciaram no primeiro semestre de 1983 (OLDIGES, 2013). O movimento possuía ligação com a Corrente Progressista da Igreja Católica, em defesa da Teologia da Libertação, e por isso ainda possui certas características do discurso católico.

Valdete Boni (2013) destaca três momentos essenciais para o movimento. Primeiramente, por uma influência da própria igreja, não houve uma aproximação dos ideais feministas, motivo pelo qual se voltou somente a questões trabalhistas. As discussões de gênero só surgiram na década de 1990, segundo momento em que o discurso passa a reforçar noções de gênero, e não só de classe. Em um terceiro momento, o MMC englobou ideais de segurança alimentar, proteção ao meio ambiente, às florestas nativas e às sementes crioulas. Em 1995, foi criada a Articulação Nacional de Mulheres Trabalhadoras Rurais - ANMTR, que reuniu agricultores ligados à Via Campesina, representados pelos seguintes movimentos: Movimentos Autônomos, Comissão Pastoral da Terra - CPT, Movimento dos Trabalhadores Rurais Sem Terra - MST, Pastoral da Juventude Rural - PJR, Movimento dos Atingidos pelas Barragens - MAB, alguns Sindicatos de Trabalhadores Rurais e o Movimento dos Pequenos Agricultores - MPA.

A Via Campesina é movimento internacional que tem como projetos a Reforma Agrária e a Soberania Alimentar, por meio da coordenação de pequenos e médios agricultores, mulheres rurais e comunidades indígenas e negras da América, Europa, Ásia e África. A ANMTR, conforme o portal eletrônico do movimento, foi marcada por mobilizações e acampamentos estaduais e nacionais, celebração de datas históricas e significativas como o dia 08 de março (Dia Internacional da Mulher) e o dia 28 de maio (Dia Internacionl de Luta pela Saúde da Mulher), entre outros, por lutas pela ampliação dos direitos previdenciários, saúde pública, um novo projeto popular de agricultura, reforma agrária, documentação, pela formação política e ideológica do movimento e pela elaboração de cartilhas, vídeos, panfletos, folhetos e cartazes. Durante a realização de um Curso Nacional que contou com a presença de mulheres de diversos estados, foi decido que o nome dado a essa organização seria Movimento de Mulheres Camponesas. 


\section{As estratégias de ação nos movimentos sociais}

A análise realizada por Thompson (1998), em sua obra Costumes em Comum, indica que o costume e a cultura só podem ser compreendidos se visualizados dentro de um contexto que priorize os processos históricos em questão. $\mathrm{O}$ autor demonstra, assim, as práticas do povo inglês do século XVIII em um contexto de resistências e acomodações das tradições consuetudinárias, bem como da emergência de mudanças comportamentais que ocorrem com a consolidação do capitalismo industrial na Inglaterra. O costume seria a prática, cuja habitualidade e execução frequente formaria o direito consuetudinário, fundado nas ações reiteradas da população. $\mathrm{O}$ autor descreve, por isso, os conflitos de classes em torno da oposição entre a defesa de costumes locais e o desenvolvimento agrário através do direito e da lei.

O autor mostra, além disso, que o costume agrário não seria uniforme, mas que estaria ambientado e influenciado por diversas variáveis por meio das quais cada classe social buscaria um maior número de vantagens. Com a pressão demográfica, o crescimento das cidades e dos empregos, o aumento do valor de mercado dos bens e uma lei que se adaptava ao "desenvolvimento" agrícola, os conflitos relacionados aos direitos comuns se ampliaram. Principalmente no século XVIII, ocorrem conflitos por conta dos cercamentos das áreas comunais. Com a reinvidicação de cercamentos dos intitulados proprietários, a classe dos plebeus começa a perder direitos conquistados através dos costumes de "tempos imemoriais", como colher das florestas comunais produtos para sua sobrevivência como lenha, turfa, respiga, e seu próprio espaço de sobrevivência.

A grande era dos cercamentos, entre 1760 e 1820, demonstra o frenesi pelo desenvolvimento agrícola em oposição à resistência dos que defendiam a economia baseada nos costumes, o que coloca o costume como lugar de conflito de classes. Exatamente pelo fato de o costume não ser imutável, mas possuir diversos significados para diferentes classes sociais, ele seria um veículo de conflito, e não de consenso. São dentro desses conflitos que evoluem as definições capitalistas do direito de propriedade. Os direitos comuns nas terras incultas eram redigidos com termos vagos ou incertos, mas durante julgamentos em tribunais ou processos de cercamento esses termos se tornavam precisos. Nos dois casos os favorecidos eram os que possuíam poder e recursos, em detrimento dos pequenos usuários. Isso baseado 
em um "espírito de progresso" que dividia o direito de uso e o usuário. O direito de uso, assim, deixa de ser um costume para se tornar propriedade.

Com a reificação do direito e com a lógica do "desenvolvimento", a lei se torna instrumento de expropriação de classe. Em nome da propriedade individual absoluta ocorre a extinção dos direitos comuns e de uso das “camadas mais baixas". Essa noção de propriedade foi reforçada por ideais como o de Locke, Sir. William Blackstone e Adam Smith. Em 1790 acontece o auge dos cercamentos, e o parlamento e a lei dão definições capitalistas à propriedade rural exclusiva. A propriedade comunal é considerada como um obstáculo ao desenvolvimento e à indústria, terra de ociosidade e de vadiagem.

Ao explorar a relação entre a lei e as ideologias dominantes em oposição aos usos do direito comum e a consciência costumeira, Thompson aponta os cercamentos como um território de conflito de classes. A lei foi utilizada como instrumento do capitalismo agrário e o cercamento parlamentar foi seu último ato, já que as relações na maioria dos locais já se encontravam monetarizadas e sujeitas às leis de mercado. As formas comunais, expressadas por John Clare como uma noção alternativa de posse, embora representassem o direito local e excluíssem estranhos daquela paróquia, simbolizavam a noção de lar e de segurança, de assistência aos pobres e de trocas de serviços e favores. Com os cercamentos os commoners se tornam "estranhos em sua própria terra” (THOMPSON, 1998).

Thompson demonstra essas disputas através de inúmeras fontes, como os processos judiciais nos quais a classe pobre lutava por seus direitos, adquiridos pelos costumes, ao adentrar os cercamentos através de escadas ou destruir parte do muro para obter acesso ao pasto, atitude pela qual comumente eram processados pelo 'proprietário' no Tribunal Senhorial:

Numa inspeção paroquiana, alguns trabalhadores podiam levar "um machado, um enxadão e uma barra de ferro [...] para demolir qualquer edificação ou cerca que tivesse sido erguida sem permissão" nas terras comunais ou incultas. Isso era tenazmente mantido como uma reivindicação legítima do direito. Mas essa é igualmente a razão de alguns infratores serem indiciados nos registros das cortes: Em Feckenham (Worcestershire), em 1789, por "demolirem, derrubarem e destruírem com podões, pás, enxadões, machados, serras" etc. catorze jardas de sebes; em Culmstock (Devon), em 1807, por entrarem num jardim e pomar com machadinhas, serras, picaretas e pás, derrubando as cercas, revolvendo a terra, armando uma tenda para impedir que o proprietário (ou pretenso proprietário) tomasse posse; em Porlock (Somerset), em 1774, por entrarem num jardim, derrubando sebes e cercas, estragando e roubando material de jardinagem. Essas ocorrências podiam ser pequenas brigas ou "tumultos", mas também podiam ser ações 
premeditadas para criar um caso que julgaria o "direito" deles. (THOMPSON, 1998, p. 101).

O autor demonstra, por meio de um estudo de Jeanette Neeson, que os tumultos eram a variedade menos comum e eficaz de oposição aos cercamentos. Havia uma variedade de protestos que se contrapunham à situação como lobbies, petições, destruição de registros, incêndios criminosos e derrubadas de cercas. Essas ações, conforme o autor, foram causa de um retardamento dos cercamentos, e muitas vezes de alteração de seus termos. Deste modo, a racionalidade da lógica capitalista foi freada pelo instituto da posse da época, bem como pelos costumes arraigados nas comunidades.

Fica claro, ainda, que não era do interesse dos commoners que os conflitos em relação aos direitos comuns nas terras incultas fossem submetidos a tribunais. Esses direitos eram, em sua maior parte, relatados de maneira vaga. Sua definição se dava de maneira exata somente nos processos de cercamento ou em julgamentos em tribunal. Tanto nos processos de cercamento quanto nos tribunais os pequenos usuários eram desfavorecidos por decisões à luz de um "espírito de progresso" que reificava os usos como propriedades. Natural a aversão dos commoners, por isso, ao encaminhamento de seus casos às instâncias mais altas das cortes, motivo pelo qual a lei era evitada, já que instrumento de desaprovação dos costumes e de expropriação de pequenos proprietários de terras (THOMPSON, 1998).

Essa variedade de ações contrárias à consolidação da propriedade absoluta na Inglaterra, longe de representarem aglomerações irracionais, constituíram-se em estratégias sociais dos pequenos proprietários. É o que apresenta Thompson (1998) quando trata da economia moral da multidão inglesa no século XVIII. Em um estudo dos motins da fome no século XVIII na Inglaterra, o autor afirma que essas ações não se reduzem a simples reações espasmódicas à fome, mas movimentos racionalmente e economicamente organizados. Há, assim, legitimidade nesses processos, já que essas ações populares carregavam um senso de defesa dos costumes da época, bem como possuíam aceitação da comunidade. O "motim" buscava apoio em práticas costumeiramente aceitas dentro dos mercados, o que conferia ao movimento a legitimidade que Thompson (1998) denomina de uma "economia moral dos pobres". Essa economia defendia um bem-estar comum que encontrava suporte na própria tradição paternalista das autoridades.

Essas estratégias de ação social são visíveis, também, na realidade brasileira. As ligas camponesas surgem em torno de uma questão agrária vinculada ao complexo 
latifúndio/minifúndio. É o que demonstra Antônio Montenegro (1964) ao relatar a história de Bubu, em Recife, na década de 1940. Com a proibição do sítio aos trabalhadores de cana e a falta de ajuda com medicamentos durante a convalescença de sua mulher, Bubu deixa seu trabalho com o senhor de engenho e rompe, assim, com os com a relação paternalista que ali existia. $\mathrm{O}$ autor deixa claro que essa atitude não ocorreu de maneira impulsiva ou impensada, mas se constituiu em estratégia que elimina a relação de dependência entre Bubu e seu patrão. É o que ele denomina “trampolinagem”, atividade relacionada à astúcia, esperteza e alteração de uma ordem opressora.

A resistência dos trabalhadores a essa dominação no meio rural, nos meados do século $\mathrm{XX}$, é o contexto no qual se insurgirão as futuras ligas camponesas. Isso ocorre, primeiramente, com a fundação, na Galileia, da Sociedade Agrícola e Pecuária dos Plantadores de Pernambuco (SAPPP). Seu objetivo era o de auxílio, a partir de um fundo de ajuda mútua, no pagamento das dívidas que os agricultores adquiriam com os proprietários de terras. Há uma preocupação desses trabalhadores, também, com a maneira com a qual seriam enterrados, motivo pelo qual a entidade assistencialista também era importante. Posteriormente, após o $1^{\text {o }}$ Congresso de Camponeses de Pernambuco, organizado pela SAPPP, esta passa a ser denominada pela imprensa de "Ligas Camponesas". A associação tinha como objetivo apontar um caráter comunista na organização.

Desde sua criação, em 1954, o movimento sofre acusações de subversão da ordem e da propriedade por parte da mídia. Em 1960, o jornalista do The New York Times, Tad Szulc, relata um nordeste incendiário, com movimentos que, à semelhança do que ocorrera com Cuba, ameaçavam a governabilidade do país e do continente. O autor evidencia, contudo, que as ações tomadas no país não se dariam diretamente em razão de uma pressão dos Estados Unidos, mas que o que aconteceu estaria de acordo com os interesses de "setores dominantes políticos, econômicos, intelectuais e religiosos" do país. Fato é que o trabalho das Ligas de rompimento das relações de exploração e dominação no campo representou uma direção alternativa face à proibição dos sindicatos rurais. As Ligas, nesse sentido, agiam apartadas de um controle estatal. A criação dos sindicatos rurais, posteriormente, é o que impossibilitará a continuidade do desenvolvimento das Ligas, com seu esvaziamento (MONTENEGRO, 2003). 
Com o Golpe Militar em 1964, o fim do complexo latifúndio/minifúndio e sua substituição pelo complexo agroindustrial, processo aqui já relatado, é instituído o Estatuto da Terra, adaptado a esse novo complexo. O Estatuto da Terra, aliado à indústria e ao fim das oligarquias rurais tradicionais, trata da reforma agrária como política econômica com o objetivo de transformação da terra em terra-capital. A reforma agrária não é mais a que havia sido proposta pelas Ligas Camponesas, mas aquela implementada pelo Estado, da agricultura vinculada à indústria e a um ideal de desenvolvimento. O Estatuto da Terra, além disso, busca trazer o Direito Agrário para dentro do âmbito do Estado. Ocorre, por meio dele, a abolição do termo "camponês" e sua substituição pela expressão "agricultor familiar". Seu intuito, da mesma maneira que a criação dos sindicatos rurais, é o de carregar as lutas e os conflitos no campo para uma perspectiva de controle estatal.

O Movimento dos Trabalhadores Rurais Sem Terra surge nessa conjuntura de reforma agrária implementada pelo Estado. A atuação do MST, por isso, diferencia-se bastante daquela visualizada nas Ligas Camponesas. É por esse motivo que Carter (2010) analisa a perspectiva histórica do movimento e sua capacidade de unir pressões sociais com negociações estatais por meio de um ativismo público. Do mesmo modo que Thompson destacou que os motins de fome na Inglaterra não se constituíam em uma força irracional, mas possuíam uma lógica legitimada pela economia de mercado da época e pelas próprias autoridades, Carter busca demonstrar que as atividades do MST não se fundavam apenas em suas sólidas crenças, mas em estratégias inovadoras, táticas e ações contenciosas contextualizadas pelas oportunidades políticas existentes.

$\mathrm{O}$ autor relaciona o desenvolvimento do movimento com um engajamento particular em conflitos sociais denominado ativismo público. Esse ativismo está organizado e inserido em uma estrutura política e suas ações são visíveis, periódicas e não violentas:

As ações promovidas pelo ativismo popular voltam-se a: (1) atrair a atenção pública; (2) influenciar as políticas do Estado por meio de pressão, do lobby e das negociações; e (3) configurar as ideias, os valores e as ações da sociedade em geral. Normalmente, as mobilizações desse tipo empregam uma série de repertórios modernos de ação coletiva, como demonstrações, marchas, petições, reuniões de discussão, greves de fome, acampamentos de protesto e campanhas eleitorais, além de atos de desobediência civil, como piquetes, bloqueios de estradas e ocupações organizadas de terra e de prédios públicos. Diferentemente de outras abordagens ao conflito social, a orientação não violenta do ativismo público faz com que ele seja compatível com a sociedade civil e proporcione um instrumento democrático legítimo para fomentar a mudança social. (CARTER, 2010, p. 203). 
Para que esse ativismo público seja possível, entretanto, o autor aponta como necessários dois requisitos, as oportunidades políticas e o acesso a recursos mobilizadores. As oportunidades políticas se caracterizam pelas organizações de poder em contextos políticos, as quais favorecem ou barram as experiências dos movimentos sociais. No caso dos recursos mobilizadores, os veículos coletivos utilizados para a atuação dos movimentos são sustentados por uma rede de recursos humanos, materiais e imateriais. A combinação desses dois elementos possibilita que os movimentos realizem exigências e negociem com o Estado. Para melhorar a pressão e as exigências realizadas, os movimentos se unem a grupos da sociedade civil e política.

Nesse sentido, o autor expõe que quando os recursos mobilizadores são baixos e as oportunidades políticas altas, há uma "confrontação desordeira" ou uma "revolta dispersada". Quando tanto os recursos mobilizadores quanto as oportunidades políticas são baixos, ocorrem "pedidos suplicantes" ou "formas cotidianas de resistência". Quando os recursos mobilizadores são altos, mas as oportunidades políticas baixas, acontece uma "luta agressiva" ou "insurgência armada". E, por fim, quando tanto os recursos mobilizadores quanto as oportunidades políticas são altos, ocorre um "engajamento crítico sustentado" ou um “ativismo público". O autor destaca, assim, que cada fase do MST no Rio Grande do Sul perpassou uma modalidade distinta de ativismo público.

Durante o primeiro período, as origens do movimento (1979-1984), as atuações do MST se encaixavam na modalidade de "pedidos suplicantes", já que o objetivo era o de atrair a atenção do público ao movimento e incentivar doações da Igreja e do Estado. Na segunda fase (1985-1994) ocorrem transgressões à ordem imposta e manifestações de uma "luta agressiva". Por fim, no terceiro período (1995-2006), o movimento amadureceu suas táticas e relações com o Estado e a sociedade civil, de modo que atingiu um "engajamento crítico sustentado" (CARTER, 2010). Desse modo, o fato é que as estratégias "sofisticadas" do Movimento dos Trabalhadores Rurais Sem Terra o levam a ser um movimento que difere das Ligas Camponesas por dialogar com o Estado e seus mecanismos, bem como o direito positivado. As ocupações realizadas pelo MST se diferenciam daquelas realizadas pelas Ligas, na medida em que buscam a criação de direitos e buscam provar, dentro da legalidade, a condição de sem terra. 


\section{As estratégias de ação social do Movimento de Mulheres Camponesas}

O Movimento de Mulheres Camponesas, conforme seu portal eletrônico, organiza-se, primeiramente, por um Grupo de Base que forma, organiza e articula as reivindicações pelos direitos da mulher camponesa e sua libertação. Duas dirigentes do grupo coordenam essa instância. As Direções Municipais organizam as atividades do MMC em seu município e coordenam as relações com outras instâncias do MMC. São constituídas por uma dirigente de cada Grupo de Base. As Direções Regionais organizam as atividades do MMC nas Regionais dos Estados e tem sua direção composta por duas dirigentes de cada município. As Direções Estaduais articulam as atividades do MMC no Estado e são compostas por duas dirigentes de cada regional. A Coordenação Nacional confere linhas políticas ao MMC, organiza suas lutas e promove relações com os Estados e suas atividades. É composta por duas participantes de cada Estado.

A Direção Executiva executa e possibilita as proposições da Coordenação Nacional, é composta por 10 participantes desta e reúne as coordenadoras das equipes de trabalho. As equipes que compõem a Direção Executiva se dividem em categorias de lutas, formação, finanças, organização, relações internacionais, relações nacionais e comunicação. A instância máxima de decisão do MMC é o Congresso ou Assembleia Nacional, que de três em três anos busca um aprofundamento das decisões de assembleias ou congressos estaduais, nacionais e regionais. O MMC possui esferas em dezoito estados federativos e é o maior movimento autônomo de mulheres camponesas, além de possuir militância espalhada por todas as regiões brasileiras. Sua estrutura de apoio conta com um Escritório Nacional com sede em Brasília/DF, e uma Secretaria Nacional com sede em Passo Fundo/RS.

O movimento propõe não só a luta contra a desigualdade de gêneros, mas um novo modelo de desenvolvimento rural. Como já foi apontado dentro do histórico do MMC, seu discurso engloba ideais como os de segurança e soberania alimentar, proteção ao meio ambiente, às florestas nativas, perpetuação das sementes crioulas, biodiversidade, agricultura familiar, reforma agrária, direitos trabalhistas e o fim da exploração, opressão, dominação e violência contra a mulher no campo. Na cartilha Sementes de Vida nas Mãos das Mulheres Camponesas (s/d), o movimento divulga a realização da Festa das Sementes, a qual coloca a recuperação das sementes como instrumento de luta pela soberania alimentar. Essas sementes 
crioulas, aperfeiçoadas por sua conservação pelos camponeses e povos indígenas, adaptaramse a diferentes ambientes, climas e regiões. Nas práticas do movimento são incentivadas as trocas de sementes, hortaliças e plantas medicinais.

A cartilha ressalta, ainda, como a modernização da agricultura, a Revolução Verde e o pacote de industrialização da agricultura implantado no Brasil nas décadas de 60 e 70 foram ineficazes para que se acabasse com a fome e a miséria no campo. O discurso do movimento atesta, por isso, a importância da soberania alimentar, na qual o povo tem autonomia para definir a produção e a distribuição de seus alimentos. Indica-se, assim, como a sabedoria popular está ligada à produção de alimentos saudáveis, enquanto a agricultura capitalista desenvolveu sementes híbridas, que só produzem bem com grandes quantidades de adubos, empobrecem o solo e provocam um desequilíbrio da natureza. A utilização dessas sementes tem como requisito, ainda, um grande custo de produção, já que necessária a aquisição de adubos químicos, agrotóxicos e implementos para a realização do plantio.

Dentro desse ideal de produção de alimentos saudáveis, um folder do movimento (Agroecologia, uma alternativa para a continuidade da vida, s/d) destaca, dentro de um projeto de agricultura camponesa, a agroecologia como uma alternativa para a continuidade da vida; a consideração das sementes crioulas como patrimônio dos povos a serviço da humanidade; a preservação da biodiversidade, das matas, florestas, nascentes, rios, fontes e recursos hídricos; a reforma agrária; o acesso e controle dos meios de produção pelos camponeses; a valorização e reconhecimento do saber popular; a ciência a serviço da vida e do bem comum; o aumento do bem-estar no campo; o respeito às diferenças e o fim da discriminação das mulheres e da classe trabalhadora; o fortalecimento da cultura camponesa; a soberania alimentar e a independência na produção, e, por fim, a valorização da agricultura camponesa por meio de políticas públicas específicas que a auxiliem. A luta histórica por políticas públicas é destacada por Hereda \& Cintrão (2006), citadas por Silva (2013):

Na década de 1980 os movimentos das mulheres rurais contribuíram significativamente para a construção de políticas públicas voltadas a redução das desigualdades de gênero na agricultura principalmente no sul e no nordeste brasileiro. As autoras afirmam que os movimentos rurais têm sido promotores de alavancamento de políticas públicas, como na luta pela terra na forma de efetivação de política de assentamentos, movimento sindical, previdência social, e crédito voltado para a agricultura familiar. (HEREDA \& CINTRÃO apud SILVA, 2013, p. 4). 
A agroecologia proposta pelo movimento como parte de seu projeto de agricultura é um instrumento de harmonização entre o ser humano e a natureza. Sua utilização se dá em favor da multiplicação e defesa da biodiversidade, e optar por esse estilo de produzir representa a incorporação de um novo modelo de vida e de uma estratégia de resistência no campo. O MMC se coloca, em Cartilha de esclarecimento sobre a reforma da Previdência Social (2016), contra a Reforma da Previdência proposta pelo PMDB, que assumiu interinamente o governo federal. Essa reforma desvincula os benefícios previdenciários do salário mínimo, conquista da classe trabalhadora que passou a ser ameaçada pela proposta. $\mathrm{O}$ movimento exige, assim, a continuidade da Previdência Pública Universal conquistada por lutas de movimentos de mulheres trabalhadoras do campo.

Em documento denominado Nenhuma trabalhadora rural sem documentos (2004), o movimento demonstra a necessidade de que as mulheres trabalhadoras rurais possuam documentação pessoal e profissional. A partir disso, a cartilha explica passo a passo como conseguir os documentos de Certidão de Nascimento, Certidão de Casamento, Carteira de Identidade, Título de Eleitora, Cadastro de Pessoa Física, Bloco de Notas de Produtora Rural, Título de Terra, Talão do INCRA e Contrato de Arrendamento, Parceria ou Comodato. Táboas (2014), por meio de uma pesquisa de campo realizada no âmbito do Movimento, constata que o MMC propõe um novo projeto de feminismo, um Feminismo Camponês Popular, cujas principais bandeiras de luta são:

a) reconhecimento e valorização do trabalho das mulheres camponesas, atividade essencial para a subsistência da família e para a manutenção da agricultura familiar; b) promoção da autonomia econômica, tendo em vista que o empoderamento das mulheres camponesas passa, muitas vezes, pela independência financeira; c) reconhecimento institucional das mulheres camponesas como sujeito da política agrária perante o estado, acesso à documentação pessoal; d) valorização da identidade das camponesas, fortalecimento da cultura, reconhecimento das formas particulares de conceber a dignidade humana e seus direitos humanos; e) libertação do machismo, compreendendo que as raízes patriarcais estão apegadas às tradições populares do campo. (TÁBOAS, 2014, p. 99-100).

As estratégias de ação do Movimento de Mulheres Camponesas, desse modo, demonstram que o movimento, da mesma maneira que o Movimento dos Trabalhadores Rurais Sem Terra é um movimento que surgiu e se desenvolveu de maneira a dialogar com as 
estruturas estatais. Isso se demonstra em sua luta pelo reconhecimento das sementes crioulas, pela instituição da reforma agrária por meio do INCRA, pela exigência de políticas públicas voltadas às mulheres camponesas, pela documentação das mulheres do campo, sua participação em sindicatos rurais, entre outros. O movimento, por isso, não se encontra apartado do Estado ou age por meio de uma lógica irracional, mas se insere em uma luta entre diferentes concepções de direitos e atua mediante um ativismo público. Dialoga, por isso, com o direito positivado, motivo pelo qual possui total legitimidade em suas ações.

\section{REFERÊNCIAS BIBLIOGRÁFICAS}

AGROECOLOGIA, UMA ALTERNATIVA PARA A CONTINUIDADE DA VIDA. In Portal Movimento de Mulheres Camponesas. Disponível em: http://www.mmcbrasil.com.br/site/materiais/download/folder_agroecologia.pdf Acesso em 15/07/2016.

BONI, Valdete. O Movimento das Mulheres Camponesas de Santa Catarina e Sua Identidade (Eco)Feminista. Seminário Internacional Fazendo Gênero 10. Anais Eletrônicos, Florianópolis, 2013. Disponivel em: http://www.fazendogenero.ufsc.br/10/site/anaiscomplementares acesso em 01/11/2015.

CARTER, Miguel. Origem e consolidação do MST no Rio Grande do Sul. In: (Org.) Combatendo a desigualdade social: O MST e a Reforma Agrária no Brasil. São Paulo: Editora UNESP, 2010. P. 199-235.

\section{CARTILHA DE ESCLARECIMENTO SOBRE A REFORMA DA PREVIDÊNCIA} SOCIAL. In Portal Movimento de Mulheres Camponesas. 2016. Disponível em: http://www.mmcbrasil.com.br/site/materiais/download/cartilha_sobre_reforma_da_previdenci a_social-2016.pdf Acesso em: 15/07/2016.

CONTE, Isaura Isabel; WESCHENFELDER, Noeli Valentina; CINELLI, Catiane. A Construção do Feminismo e da Identidade Camponesa no Movimento de Mulheres Camponesas. Seminário Internacional Fazendo Gênero 9. Anais Eletrônicos, Florianópolis, 2010. Disponível em http://www.fazendogenero.ufsc.br/site/anaisfg9 acesso em 01/10/2015.

GROSSI, Miriam Pillar. Discours sur les Femmes Battues: representations de la violence sur les femmes au Rio Grande do Sul. Paris: Université Paris V, Sciences HumainesSorbonne, 1988. 
LUSA, Mailiz Garibotti. Cotidianidade e Militância das Mulheres Camponesas - A Construção de Identidades e a Conquista de Direitos Sociais para o Campo. Seminário Internacional Fazendo Gênero 9. Anais Eletrônicos, Florianópolis, 2010. Disponível em http://www.fazendogenero.ufsc.br/site/anaisfg9 acesso em 01/10/2015.

MARTINS, José de Souza. O tempo da fronteira: retorno à controvérsia sobre o tempo histórico da frente de expansão e da frente pioneira. In: Martins, José de Souza. Fronteira: a degradação do Outro nos confins do humano. São Paulo Editora Hucitec, 1997. P.147-203.

MENEGHEL, S. N; MUELLER, B. COLLAZIOL, M. M. de Quadros. Repercussões da Lei Maria da Penha no Enfrentamento da Violência de Gênero. In. Revista Ciência \& Saúde Coletiva. Vol. 18, número 3, Rio de Janeiro, Mar. de 2013. Disp. em: http://www.scielo.br/scielo.php?pid=S1413-81232013000300015\&script=sci_arttext Acesso em 05/05/2015.

MONTENEGRO, Antônio Torres. Ligas Camponesas e sindicatos rurais em tempo de revolução. In: FERREIRA, Jorge. \& DELGADO, Lucilia de Almeida Neves. (orgs.) O Brasil Republicano: O tempo da experiência democrática - da democratização de 1945 ao golpe civil-militar de 1964. Rio de Janeiro: Civilização Brasileira, 2003. p. 241-271.

MULLER, Geraldo. Indústria e agricultura no Brasil: do latifúndio-minifúndio ao CAI. \& Formulações gerais sobre o CAI. \& A agricultura Brasileira no CAI. In: MULLER, Geraldo. Complexo Agroindustrial e modernização agrária. São Paulo: Editora Hucitec, 1989. p. 27-107.

NENHUMA TRABALHADORA RURAL SEM DOCUMENTOS. In Portal Movimento de Mulheres Camponesas. 2004. Disponível em:

http://www.mmcbrasil.com.br/site/materiais/download/cartilha_documentacao.pdf Acesso em: $15 / 07 / 2016$.

OLDIGES, Monica Maria Tourinho. As Representações Sociais das Mulheres do Movimento das Mulheres Camponesas sobre as Desigualdades Sociais e s Diversidades Socioculturais. Seminário Internacional Fazendo Gênero 10. Anais Eletrônicos, Florianópolis, 2013. Disponivel em: http://www.fazendogenero.ufsc.br/10/site/anaiscomplementares acesso em $\underline{01 / 11 / 2015}$.

PALMEIRA, Moacir. Modernização, Estado e Questão Agrária. In: HTTP://www.scielo.br/pdf/ea/v3n7a06.pdf. Acessado em 09/06/2016.

Portal Movimento de Mulheres Camponesas. Disponível em: http://www.mmcbrasil.com.br/site/ Acesso em: 10/07/2016

RINALDI, Alessandra de Andrade. Violência e Gênero - A Construção da Mulher como Vítima e seus Reflexos no Poder Judiciário: A Lei Maria da Penha como um caso exemplar. 
In. KLEVENHUSSEN, Renata Braga (org). Direito Público e Evolução Social. $1^{\text {a }}$ Série. Rio de Janeiro: Lumen Juris, 2007, v.1, p. $39-61$.

SEMENTES DE VIDA NAS MÃOS DAS MULHERES CAMPONESAS. In: Portal Movimento de Mulheres Camponesas. Disponível em:

http://www.mmcbrasil.com.br/site/materiais/download/cartilha_sementes.pdf Acesso em: $15 / 07 / 2016$.

THOMPSON, E.P. Costume, lei e direito comum. In: Costumes em comum: estudos sobre a cultura popular tradicional. São Paulo: Companhia das Letras, 1998, p. 86149.

SILVA, Adilson Tadeu Basquerote. A Participação Feminina na Agricultura Agroecológica: um estudo de caso. Seminário Internacional Fazendo Gênero 10. Anais Eletrônicos, Florianópolis, 2013. Disponivel em: http://www.fazendogenero.ufsc.br/10/site/anaiscomplementares acesso em 01/11/2015.

TÁBOAS, Ísis D. M. Z. Viver sem violência doméstica e familiar: a práxis feminista do Movimento de Mulheres Camponesas. Brasília, 2014. 165p. Dissertação de Mestrado Programa de Pós-Graduação em Direitos Humanos e Cidadania do Centro de Estudos Avançados Multidisciplinares, Universidade de Brasília.

WANDERLEY, Maria de Nazareth Baudel. Raízes Históricas do Campesinato Brasileiro. In: Anais do XX Encontro Anual da Anpocs. Caxambu: Anpocs, 1996, p. 02-18. 